\title{
A estrutura da autoconsciência na filosofia da mente de John Searle
}

\author{
The structure of self-consciousness in \\ John Searle's philosophy of mind
}

*Tárik de Athayde Prata

\begin{abstract}
Resumo: A tese defendida no presente artigo é que a autoconsciência, na visão de Searle é uma caraterística (não explicada) do campo unificado de consciência. Após uma discussão de três distinções a respeito da consciência propostas por Rosenthal (seção 1), é discutido o conceito de consciência de Searle - como um fenômeno qualitativo, subjetivo e unificado - e o caráter holístico desse conceito (seção 2). A discussão que Searle faz dos conceitos de autoconsciência e de introspecção (seção 3) mostra que ele acredita que uma autoconsciência implícita é uma característica constitutiva do campo unificado de consciência.
\end{abstract}

Palavras-chave: autoconsciência; introspecção; explanação; campo unificado.

\begin{abstract}
The thesis of the paper is that Self-consciousness in Searle's view is a (not explained) feature of the unified field of consciousness. After a discussion of three distinctions about consciousness proposed by Rosenthal (section 1), Searle's concept of consciousness - as a qualitative, subjective and unified phenomenon - and the holistic character of this concept are discussed (section 2). Searle's discussion of the concepts of Self-consciousness and Introspection (section 3) shows that he believes in implicit self-consciousness as a constitutive feature of the unified field of consciousness.
\end{abstract}

Keywords: self-consciousness; introspection; explanation; unified field.

\footnotetext{
* Graduado em Psicologia e Mestre em Filosofia Contemporânea pela Universidade Federal do Ceará (UFC). Doutor em Filosofia pela Ruprecht-Karl Universität Heidelberg (Alemanha). Professor Adjunto do Departamento de Filosofia e Coordenador do Mestrado em Filosofia da Universidade Federal de Pernambuco (UFPE). <tarik.de_athayde_prata@alumni.uniheidelberg.de>
} 
ob certo ponto de vista, é bastante intuitivo considerar a consciência como uma característica intrínseca do mental. Não é verdade que, se perdermos a consciência (se ficarmos desacordados) nossa vida mental parece entrar em suspenso? Se nos encontramos (conscientemente) em um certo estado mental, como uma crença ou um desejo, esse estado não nos torna conscientes de algo? Entendo que esses são elementos de nossa vivência cotidiana que tornam plausível a visão que iguala a nossa vida psicológica à consciência. A verdade é que uma série de conhecimentos a respeito da mente vão de encontro a essa intuição (da consciência como o aspecto fundamental da vida psíquica). ${ }^{1}$ De fato, é muito difícil negar que fenômenos mentais inconscientes desempenham um papel importante em nossa vida mental (SEARLE, 1992, p. 151 [217]2; SEARLE, 2004, p. 250), mas, mesmo assim, é interessante e proveitoso investigar conceitos de consciência que tornam plausível essa intuição, pois (sem negar a existência de fenômenos mentais inconscientes) é importante tentar compreender aspectos da consciência que a fazem (pelo menos) parecer essencial para a nossa vida psicológica.

Um aspecto da consciência que age nesse sentido (fazendo-a parecer essencial) é a autoconsciência que, de acordo com uma antiga tradição filosófica ${ }^{3}$, acompanha nossos estados mentais. Quando estamos conscientes, e possuímos algum tipo de consciência de algo (seja ao modo de uma crença, de um desejo, de uma emoção, etc.) é bastante razoável pensar que essa consciência de algo, se manifesta a nós de uma determinada maneira. Não é nada absurdo dizer que, ao mesmo tempo em que tenho alguma forma de consciência a respeito de algo, esta mesma consciência de algo se manifesta a mim de uma determinada maneira, ou é apreendida por mim de um determinado modo.

É bem verdade que essa apreensão dos estados eventos e processos mentais ${ }^{4}$ pode ocorrer ao modo de uma reflexão, ou seja, no modo de um retorno do foco da atenção, que se desloca do mundo extramental e se

\footnotetext{
1 "As pessoas possuem, é claro, muito mais crenças e preferências, a cada momento, do que as que ocorrem na sua corrente de consciência. E as crenças não conscientes tem de ter propriedades intencionais." (ROSENTHAL, 1986, p. 334). "Nós podemos determinar a presença de estados mentais inconscientes através de suas conexões causais com o comportamento e estímulos, e com outros estados mentais, sejam conscientes ou não." (ROSENTHAL, 1986, p. 338).

2 O primeiro número de página é o da edição na língua original, enquanto o número entre colchetes é o da página da tradução consultada para a redação do presente trabalho.

3 "A filosofia moderna de Descartes até Hegel acreditou com o conceito de autoconsciência não apenas ter descoberto o princípio metódico diretor da Filosofia, mas também o fundamento para uma existência esclarecida e autônoma." (TUGENDHAT, 1981, p. 9). As citações em língua estrangeira foram traduzidas pelo autor do presente trabalho.

4 As noções de estado, evento e processo podem ser empregadas para expressar a existência dos fenômeno mentais. A noção de estado sugere uma permanência, enquanto a noção de evento sugere uma mudança, ao passo que a noção de processo sugere uma conexão articulada. Jaegwon Kim (1996, p. 6) caracteriza essas três noções com base no conceito de
} 
volta para os próprios estados (eventos e processos) mentais que o sujeito vivencia. Em lugar de, por exemplo, apreciar uma bela paisagem, posso deslocar o foco de minha atenção, retirando esse foco da paisagem e fazendo-o retornar para a minha própria experiência de vislumbrar aquele cenário. A reflexão, certamente, é um modo possível como podemos apreender nossos próprios estados mentais. Entretanto, não é razoável pensar que ela seja o único modo, pois, na verdade, durante a maior parte do tempo, vivenciamos nossos estados mentais com o foco da atenção voltado para "fora", para o mundo extramental.

Mas se estou consciente e, ao mesmo tempo, tenho consciência de algo, essa minha relação psicológica com um objeto ou um estado de coisas extramental (uma relação marcada pela intencionalidade ${ }^{5}$ ) tem que ser apreendida por mim de algum modo, mesmo se meu foco de atenção está no mundo "externo", do contrário, não parece possível dizer que há, propriamente, consciência de algo. Se estou em uma relação intencional com algo, (seja uma relação de acreditar, de desejar, de temer, etc.) mas não apreendo essa relação, então se trata de uma relação intencional inconsciente. Como será discutido a seguir, se uma consciência de algo é uma relação psicológica de um sujeito com um estado de coisas extramental, essa relação tem que se doar ao sujeito, tem que ser apreendida por ele, do contrário, não haveria consciência. Sendo assim, torna-se plausível a ideia de que há uma apreensão pré reflexiva, que apreende o estado mental no qual me encontro, independentemente de qualquer reflexão. Grandes pensadores do passado defenderam essa perspectiva. Para citar apenas dois exemplos, Franz Brentano defendeu que toda consciência de algo se apreende na forma de uma percepção interna, uma representação indissociavelmente unida à representação de um objeto externo (BRENTANO, 1924, p. 179 [127]); e Jean-Paul Sartre afirmou que toda consciência de algo é consciência de si na exata medida em que é consciência de um objeto transcendente (SARTRE, 1966, p. 24 [188]).

John R. Searle, um dos mais importantes nomes da filosofia analítica, e autor cujas ideias exerceram significativa influência nos debates em

instanciação de uma propriedade. Um estado é a instanciação continuada de uma propriedade, ao longo de determinado período. Um evento é o acontecimento da mudança de propriedades, o momento em que uma propriedade é substituída por outra, enquanto um processo é uma conexão articulada de permanências e mudanças de propriedades. Um exemplo de estado mental seria a permanência de uma sensação, de uma crença, de ou de um desejo, ao longo de um determinado período. Um exemplo de evento mental seria o instante em que uma sensação é substituída por outra, ou o instante em que uma percepção se desvanece, substituída por uma lembrança. Um exemplo de processo mental seria uma atividade articulada, como um planejamento de ação futura, ou um cálculo matemático.

5 Searle caracteriza a intencionalidade como "aquela propriedade de estados mentais pela qual eles são dirigidos a, ou são a respeito de, objetos e estados de coisas no mundo." (SEARLE, 2002, p. 44 [64-65]). 
filosofia da mente, não se cansa de enfatizar a importância da consciência no domínio dos fenômenos mentais. Nesse sentido, ele é um defensor da intuição que iguala nosso psiquismo à consciência, pois ele defende a ideia de que "não há como estudar os fenômenos da mente sem, implícita ou explicitamente, estudar a consciência. A razão básica disso é que realmente não temos noção do mental independentemente de nossa noção de consciência" (SEARLE, 1992, p. 18 [31]). Para Searle, a consciência é, simplesmente, o fenômeno mental mais importante de todos, pois todos os outros só podem ser compreendidos como, propriamente, mentais por meio de suas relações com a consciência (SEARLE, 1992, p. 84 [125-26]). Esse ponto de vista leva Searle a defender uma visão disposicional dos fenômenos mentais inconscientes, ou seja, a visão de que tais fenômenos (enquanto permanecem inconscientes) existem na forma de disposições para a causação de fenômenos mentais conscientes. ${ }^{6}$

$\mathrm{E}$ é bastante interessante investigar o modo como esse expoente da filosofia analítica lida com o tema da autoconsciência, pois ele defende que, em um sentido ordinário, é falso que todo estado de consciência é autoconsciente, mas ao mesmo tempo ele acredita que, em um sentido técnico, bastante especial, é verdadeiro que toda consciência envolve autoconsciência. Coloca-se então a pergunta sobre o que é a autoconsciência para Searle. Qual a sua estrutura? Qual a relação da autoconsciência com o procedimento reflexivo, ou seja, com a introspecção?

O caso é que ele não concebe a consciência apenas como uma propriedade, seja de criaturas, seja de estados mentais (embora esse aspecto da consciência tenha lugar em suas elaborações). Ele vê a consciência como um fenômeno global, um fenômeno unificado que subjaz à multiplicidade de fenômenos mentais, e essa visão levanta uma série de dificuldades para que se possa compreender o que é, para Searle, a autoconsciência, bem como para compreender a relação da autoconsciência com o fenômeno conexo da introspecção.

$\mathrm{Na}$ visão dele, todo estado de consciência tem um aspecto qualitativo, um modo qualitativo como ele é vivenciado, como ele é sentido, e tal aspecto implica que há um sujeito que vivencia, sente, essa experiência consciente, sendo que toda experiência é vivenciada como uma unidade, que articula uma multiplicidade de estados mentais. Qualitatividade, subjetividade e unidade são vistas por Searle como facetas de uma única característica, que seria a característica essencial da consciência:

6 Apesar de extremamente interessante, o tema das consequências da teoria da autoconsciência sobre essa visão do inconsciente não será abordada aqui, por motivos de espaço e de direcionamento temático. A esse respeito cf. Prata (2017). 
o fato de ela existir como um campo unificado de experiência qualitativa e subjetiva (SEARLE, 2002, p. 39 [56-57]; SEARLE, 2004, p. 136-137; SEARLE, 2015, p. 47). Nessa visão holística da consciência, ou seja, uma visão da consciência enquanto uma totalidade unificada, é necessário um certo esforço para identificar os elementos que efetivariam a autoconsciência pré reflexiva, pois tais elementos estão, de algum modo, integrados a uma totalidade complexa.

A tese defendida no presente trabalho é que a autoconsciência, na filosofia de Searle, é uma característica do campo unificado de consciência, uma vez que a integração a esse campo faz com que todo estado (evento e processo) mental se doe implicitamente ao sujeito consciente, e uma vez que a introspecção, para Searle, envolve uma relação entre dois estados de consciência, que estão, ambos, integrados ao campo unificado, de forma que é esse campo que, de certo modo, possibilita a introspecção. O problema é que a maneira como o campo unificado possibilitaria a doação implícita dos estados conscientes para o sujeito não é explicada, o que é um indício de que a visão de Searle da consciência como a essência da mente (o tipo de visão que David Rosenthal considera "cartesiana" - cf. ROSENTHAL, 1986, p. 330-131) de fato é um obstáculo para uma explicação conceitual da consciência.

Para identificar os elementos que delineiam essa concepção de Searle, será seguido o seguinte percurso: primeiramente, serão discutidas três distinções a respeito da consciência, propostas por Rosenthal, a saber: as distinções entre (a) consciência de criatura e consciência de estado; (b) consciência intransitiva e consciência transitiva; e (c) consciência introspectiva e não introspectiva. Essas três distinções irão ajudar a elucidar certos aspectos que estão presentes na teoria de Searle, esclarecendo o compromisso dele com a ideia de uma apreensão consciente anterior a qualquer reflexão. Em segundo lugar, será discutido o conceito de consciência articulado por Searle, que ele apresenta não como resultado de uma definição analítica, mas de uma simples "definição de senso comum", ou seja, uma definição baseada em exemplos que apenas delimita o fenômeno que será objeto de futura investigação. A discussão desse conceito de consciência evidenciará a maneira holística, totalizante, como Searle entende a consciência, delineando a estrutura maior, dentro da qual teremos de procurar a autoconsciência pré reflexiva e a introspecção. Em seguida, serão examinadas as colocações de Searle a respeito dos conceitos de autoconsciência e de introspecção, tanto suas objeções ao uso comum desses conceitos quanto sua consideração de seus aspectos positivos. Através desse exame será evidenciado o modo como Searle vê os estados (eventos e processos) mentais (que 
ocorrem como "parte"7 de um campo unificado de consciência) enquanto estados que se manifestam implicitamente à consciência do sujeito, e é exatamente aí que a ideia de uma autoconsciência pré reflexiva se encaixa na teoria da consciência articulada por Searle. Por fim, nas considerações finais, será discutida a maneira como a visão da consciência como sendo a essência da mente parece inviabilizar uma explanação da consciência, em geral, e da autoconsciência pré reflexiva, em particular.

\section{Três distinções a respeito da consciência}

Pensando em estados de consciência bem determinados, situados em porções específicas do espaço e em períodos específicos do tempo ${ }^{8}$, empregamos a palavra "consciência" para designar um certo tipo de propriedade, que pode, por um lado, dizer respeito ao seu portador de modo independente de outras entidades, ou pode, por outro lado, ser uma propriedade que relaciona seu portador com outras coisas. Se a consciência é pensada como uma propriedade, uma primeira questão importante é a de saber que tipo de coisa é, em cada caso, o portador dessa propriedade. Usualmente, atribuímos consciência - ou empregamos o predicado "consciente" - a respeito de dois tipos de entidades: criaturas, por um lado, e estados mentais dessas criaturas, por outro lado. Trata-se aqui da distinção proposta por David Rosenthal (1997) entre consciência de criatura (creature consciousness) e consciência de estado (state consciousness). ${ }^{9}$

Em certas circunstâncias, empregamos o predicado "consciente" a respeito de pessoas (ou outras criaturas conscientes, como animais), para dizer que elas estão despertas, capazes de perceber e, eventualmente, interagir com o ambiente circundante (p. ex: "mesmo após a queda, o piloto permaneceu consciente"). Em outras circunstâncias, empregamos o

7 Na verdade, Searle tende a rejeitar a metáfora da relação parte todo, como será discutido a seguir (cf. SEARLE, 2002, p. 55 [84]).

8 Searle defende que os estados mentais conscientes, em última instância, são fenômenos físicos, pois "eles estão localizados no espaço do cérebro em certos períodos de tempo" (SEARLE, 2004, p. 117).

9 "Dois assuntos são frequentemente confundidos nas discussões sobre a consciência. uma questão é: o que é para um estado mental ser consciente. Supondo que nem todos os estados mentais são conscientes, nós queremos saber como os estados conscientes se diferenciam daqueles que não são. $\mathrm{E}$ ainda que todos os estados mentais fossem conscientes, nós ainda perguntaríamos em que consiste a sua consciência. Denominamos essa a questão da consciência de estado. Esse será meu principal tema no texto que segue. Mas nós não descrevemos apenas estados mentais como sendo conscientes ou não; nós também atribuímos consciência a criaturas. Assim, existe uma segunda questão, a questão sobre o que é para uma pessoa ou outra criatura ser consciente, ou seja, como criaturas conscientes se diferenciam daquelas que não são conscientes. Denominamos esta a questão da consciência de criatura." (ROSENTHAL, 1997, p. 729). 
predicado "consciente" a respeito de estados mentais que são vivenciados por um indivíduo consciente.

Não é algo nada ousado afirmar que, a cada instante, todo indivíduo consciente se encontra em um enorme número de estados mentais que ele não vivencia. Se, por exemplo, estou me deslocando apressado pela cidade, para tentar resolver um problema urgente, é bastante improvável que eu pense no número do apartamento em que eu resido (a não ser que essa informação seja, de algum modo, relevante para a resolução do problema), embora não seja razoável negar que eu sei qual é esse número. Sendo assim, é razoável designar o estado mental do meu saber sobre o número do apartamento em que resido como um estado inconsciente, ao passo que outros estados mentais em que eu me encontro (p. ex. minha percepção do caminho que estou percorrendo) podem ser estados conscientes.

Mas trata-se aqui de casos em que a propriedade de ser consciente (seja de uma criatura, seja de um estado mental) é algo que diz respeito ao seu portador de um modo, em certo sentido, isolado, pois a propriedade pertence ao portador de um modo que não leva em consideração relações desse portador com outras entidades. Porém, há um outro sentido da palavra "consciência" que envolve certo tipo de relação com outras coisas. Em certas circunstâncias, dizemos que alguém está consciente de algo. Podemos dizer que alguém, p. ex., sabe que conseguiu um emprego, e está alegre por ter conseguido. Podemos dizer que um amigo está ciente do problema que terá de resolver, ou que uma outra pessoa tem medo do desaquecimento da economia. No uso desses termos psicológicos intencionais (saber, alegria, medo, etc.) está implícita uma atribuição de consciência ao sujeito no sentido de uma relação desse sujeito com algum objeto ou estado de coisas extramental. Isso significa que, em situações como as que acabam de ser mencionadas, é razoável dizer que os estados mentais em questão (um determinado saber ou uma determinada emoção, como alegria ou medo) consistem no modo de relação intencional do sujeito consciente com aqueles objetos ou estados de coisas extramentais. Para expressar a diferença entre esse uso, por assim dizer, relacional da palavra "consciência" e o uso que discutimos acima (no qual o portador é concebido de um modo isolado) Rosenthal propõe a distinção conceitual entre consciência transitiva (transitive consciousness) - isto é, a consciência de algo - e consciência intransitiva (intransitive consciousness). ${ }^{10}$

10 "Colocando a consciência de criatura de lado, podemos distinguir duas maneiras como usamos a palavra 'consciente'. Um é quando falamos de nosso estar consciente de alguma coisa. Por causa do objeto direto, devo chamar esse uso de transitivo. Mas nós também aplicamos o termo 'consciente' a estados mentais, para dizer que eles são estados conscientes. Isso é o 
Em suma, o predicado "consciente" pode ser empregado tanto a respeito de criaturas quanto a respeito de estados mentais, havendo uma clara relação entre esses dois tipos de consciência, na medida em que apenas uma criatura consciente pode vivenciar estados mentais conscientes, estados estes que não poderiam estar conscientes se a criatura estivesse desacordada (p. ex. em um sono sem sonhos ou sob anestesia geral). Além disso, a palavra "consciência" pode ser usada para designar não apenas propriedades intransitivas de criaturas e estados mentais (propriedades que não relacionam tais criaturas e estados com alguma outra coisa), mas também para designar propriedades transitivas dessas criaturas e estados mentais (propriedades que as colocam em uma relação psicológica com algo). E também essas formas transitivas de consciência desfrutam de uma relação estreita, pois um sujeito só pode ser transitivamente consciente - isto é, ser consciente de algo - se ele se encontrar em um estado mental que seja consciência transitiva - isto é, seja consciência de algo.

Mas além da distinção entre (a) consciência de criatura e consciência de estado, e da distinção entre (b) consciência intransitiva e consciência transitiva, há uma terceira distinção conceitual que é bastante proveitosa para a nossa compreensão do fenômeno da consciência humana. Para entender essa terceira distinção, devemos considerar que em algumas circunstâncias, quando um sujeito está consciente e, portanto, vivencia diversos estados mentais que são consciência transitiva de algo (como crenças, desejos, intenções e emoções), sua atenção está focada nos objetos e estados de coisas extramentais a respeito dos quais seus estados mentais são. Em tais circunstâncias, enquanto o sujeito está consciente e, assim, alguns de seus estados mentais estão conscientes, no que tais estados são a respeito de algo, o sujeito está focado nesse algo, e não em si mesmo ou em seus próprios estados mentais (SEARLE, 1992, p. 142 [204-5]).

Enquanto me desloco apressado pela cidade, na tentativa de resolver um problema urgente, embora eu esteja consciente, e embora meu saber a respeito do problema esteja consciente (pois estou empenhado em

que eu rotulei consciência de estado. A falta de um objeto direto sugere chamar esse uso de intransitivo. Esse uso intransitivo tem lugar somente quando falamos de estados mentais, ao passo que nós falamos de estar consciente, transitivamente, tanto de coisas físicas quanto mentais. Nós podemos estar transitivamente conscientes de uma pedra, de uma sinfonia, ou de um estado mental." (ROSENTHAL, 1997, p. 737). O autor admite que podemos fazer o uso intransitivo a respeito de criaturas (um exemplo seria: "Pedro está consciente"), mas ele evita esse uso acerca de criaturas, porque nesse caso não haveria, segundo ele, uma diferença entre transitivo e intransitivo. Em outras palavras, Rosenthal parece se negar a dizer algo como "Pedro está consciente de sua doença" (um uso transitivo a respeito de uma criatura). Mas é digno de nota que outros autores, como Kriegel (2004, p. 183), aceitam esse uso. 
resolvê-lo), estou, em certo sentido, esquecido de mim mesmo, e não atento aos meus próprios estados mentais conscientes, pois meu foco de atenção está em algo extramental.

Se chamarmos reflexão o esforço deliberado de retornar a atenção sobre si mesmo, ou sobre os próprios estados mentais, ou chamarmos de introspecção a tentativa de "olhar" (spectare) para "dentro" (intro) de si mesmo, podemos caracterizar esse primeiro tipo de consciência como consciência irrefletida (SARTRE, 1966, p. 24 [189]) ou consciência não introspectiva (ROSENTHAL, 1997, p. 730), pois trata-se, aqui, de situações nas quais, embora o sujeito esteja consciente e, portanto, vivencie estados mentais conscientes, não há nenhum esforço de reflexão ou introspecção. ${ }^{11}$

Porém, do mesmo modo que, quando somos conscientes de algo, podemos deslocar o foco de nossa atenção de um objeto para outro (p. ex., quando assisto a um belo pôr do sol posso, a qualquer instante, deslocar minha atenção para qualquer ponto da paisagem, assim como posso deslocar minha atenção para alguma lembrança do passado ou para alguma expectativa do futuro), da mesma maneira podemos deslocar nossa atenção para nós mesmos (enquanto sujeitos conscientes) ou para algum de nossos estados mentais. Enquanto assisto ao pôr do sol, posso deslocar minha atenção para mim mesmo, enquanto sujeito observador daquela cena, ou para a minha própria experiência de contemplar aquele pôr do sol. Em tais situações, pode-se dizer que há consciência refletida (SARTRE, 1966, p. 28 [191]) ou introspectiva (ROSENTHAL, 1997, p. 730).

As três distinções esboçadas acima nos ajudam a compreender com mais clareza diversas nuances do fenômeno da consciência humana. Se uma criatura está inconsciente, completamente desacordada, essa criatura não possui fenômenos mentais conscientes, embora ela possa se encontrar em diversos estados mentais (inconscientes). Se uma criatura está consciente, ela certamente vivencia uma série de estados mentais conscientes. No exato instante em que alguns de seus fenômenos mentais estão conscientes, certamente inúmeros outros permanecem desprovidos de consciência. Por outro lado, se uma criatura está consciente de algo,

11 "Será útil traçar uma segunda distinção preliminar. Quando prestamos atenção deliberadamente ao estado mental no qual nos encontramos, estamos introspectivamente conscientes desse estado. Isso é diferente do modo como estados mentais são conscientes quando não estamos deliberadamente focando nossa atenção sobre eles. Introspecção é consciência atenta e deliberada de nossos estados mentais. É algo relativamente raro, e é algo mais elaborado do que a maneira na qual estados mentais são ordinariamente conscientes. Quando realizamos introspecção, não estamos apenas cientes [aware] do estado mental em que estamos, nós estamos cientes de estarmos cientes dele. A diferença entre consciência introspectiva e não introspectiva emerge vividamente se notarmos que, quando um estado é consciente de modo não introspectivo, ele normalmente tem o potencial de ser um objeto de introspecção" (ROSENTHAL, 1997, p. 730). 
o foco de sua atenção pode estar no domínio extrapsíquico, ou pode estar voltado para ela mesma (enquanto criatura dotada de certas características psicológicas) ou para seus estados mentais. A tentativa de exame deliberado das próprias características psicológicas, por um lado, ou dos próprios estados mentais, por outro lado, é uma fonte indispensável de conhecimento a respeito de nossa vida mental, mas o fato de o foco de nossa atenção não poder estar em muitos objetos ao mesmo tempo, já indica o quanto a nossa consciência (nos diversos aspectos discutidos acima) é algo limitado, evidenciando o caráter inevitável de fenômenos mentais inconscientes em nossa vida mental.

De posse dessas distinções, estaremos em melhor situação para avaliar a teoria da consciência de Searle, e para esclarecer o modo como a tese de que há uma autoconsciência pré reflexiva encontra lugar em sua visão geral a respeito da consciência. Poderemos esclarecer como ele concebe a distinção entre criaturas e seus estados mentais, e também como ele concebe o caráter transitivo (ou não) da consciência, e principalmente, poderemos esclarecer o ponto de vista dele a respeito da introspecção (ou reflexão - cf. ROSENTHAL, 1986, p. 337), o que é fundamental para podermos elucidar sua concepção sobre a autoconsciência pré reflexiva.

\section{O conceito de consciência de Searle}

Em diversos escritos, Searle renuncia à possibilidade de oferecer uma definição analítica da consciência (seja em termos de gênero e diferença, seja em termos de condições necessárias e suficientes), e elabora uma definição baseada em exemplos, que apenas delimita empiricamente o fenômeno a ser estudado. Nesse sentido, ele afirma:

Por "consciência" eu entendo simplesmente aqueles estados subjetivos de sensibilidade [sentience] ou ciência [awareness] que começam quando alguém acorda pela manhã de um sono sem sonhos e continuam através do dia até que esse alguém adormeça à noite, entre em coma, morra ou se torne de outro modo, como diria alguém "inconsciente" (SEARLE, 2002a, p. $7[1-2]) .{ }^{12}$

Passadas mais de duas décadas, ainda encontramos nos trabalhos de Searle a mesma concepção de consciência. Em seu livro recente sobre a teoria da percepção, ele continua a caracteriza-la como a série de estados, eventos e processos que se sucedem ao longo do período em que um sujeito está consciente:

12 Trata-se aqui de uma citação do texto "O problema da consciência", publicado originalmente em 1993. 
Consciência consiste em todos os nossos estados (processos, eventos, etc.) de sentimento [feeling] ou sensibilidade [sentience] ou ciência [awareness]. Eles tipicamente começam quando acordamos de um sono sem sonhos ou de alguma outra forma de inconsciência, e continua até que nos tornamos "inconscientes" de novo. Sonhos são uma forma de consciência, embora bastante diferentes da consciência desperta. A característica absolutamente essencial da consciência é que para todo estado consciente há um modo como se sente [it feels like] estar nesse estado [to be in that state] (SEARLE, 2015, p. 46-47).

Vemos aqui a ênfase que ele dá ao aspecto qualitativo da experiência, aspecto que resulta na subjetividade da consciência que, por sua vez, implica a sua unidade. É importante perceber que, sob um certo ponto de vista, a consciência é uma propriedade do organismo que a instancia ${ }^{13}$, pois Searle a concebe como uma propriedade do sistema nervoso central no macronível, que é causada por processos cerebrais no micronível. De acordo com ele:

Consciência, em resumo, é uma característica biológica de cérebros de seres humanos e determinados animais. É causada por processos neurobiológicos, e é tanto uma parte da ordem biológica natural quanto quaisquer outras características biológicas, como a fotossíntese, a digestão ou a mitose (SEARLE, 1992, p. 90 [133] - grifado no original).

Sob esse ponto de vista, a consciência é uma propriedade de um organismo, instanciada quando as devidas condições neurobiológicas estão dadas, o que corresponde razoavelmente ao conceito de consciência de criatura proposto por Rosenthal. ${ }^{14}$ Por outro lado, a visão de Searle sobre a relação entre os estados (eventos e processos) mentais e a consciência não corresponde à visão de Rosenthal, pois, para este, a consciência pode ser entendida como uma propriedade de estados mentais, uma propriedade decorrente do monitoramento de um determinado estado mental por um pensamento de nível superior (Higher Order Thought), ou seja, um pensamento que é a respeito daquele estado mental que ele torna consciente (ROSENTHAL, 1986, p. 335; ROSENTHAL, 1997, p. 740-41). Já na visão de Searle, a consciência, enquanto um campo

13 "Instanciar" significa "exemplificar" uma propriedade, ou seja, possuir essa propriedade em dadas circunstâncias.

${ }^{14}$ É interessante notar que David Chalmers, considera a diferença entre o sono e a vigília como um dos problemas fáceis a respeito da consciência, e ele defende que a explanação dessa diferença pode ser encontrada por meio de estudos de neurociência: "Para uma explanação do sono e da vigília, será suficiente uma adequada explanação neurofisiológica dos processos responsáveis pelo comportamento contrastante do organismo nesses estados." (CHALMERS, 1995, p. 201). 
unificado de experiência qualitativa e subjetiva, é ontologicamente anterior aos estados mentais conscientes, ou seja, a consciência já existe antes que os estados, eventos e processos mentais venham a existir.

Para fazer uma comparação mais clara dessas duas visões, é importante expor, mesmo que rapidamente, as linhas básicas da teoria de Rosenthal sobre a consciência como uma propriedade de estados mentais. Em nossa vida psíquica, possuímos uma larga série de estados, eventos e processos mentais (como percepções, crenças, desejos, emoções, etc.) que são a respeito de objetos e estados de coisas no mundo extramental (estados de coisas como o fato de que Barack Obama foi o presidente dos Estados Unidos no ano de 2016, ou a hipótese de que o P.I.B. brasileiro irá aumentar no ano que vem). Nossos estados mentais (numa visão como a de Rosenthal) podem existir independentemente de estarem sendo monitorados, o que significa que eles podem existir de maneira inconsciente. Mas de acordo com as teorias de monitoramento de segunda ordem, nossos estados mentais se tornam conscientes quando são monitorados e, na versão de Rosenthal, esse monitoramento é efetuado por pensamentos, que são acerca de determinados estados mentais, que se tornam conscientes em um dado momento. Quando um estado mental é monitorado por um pensamento acerca dele, ele se torna consciente, sendo que o foco da atenção se volta para o estado de coisas extramental, acerca do que o estado mental é (o estado de coisas ao qual ele "se dirige"). Na teoria de Rosenthal, a introspecção, o exame atento e deliberado dos próprios estados mentais (ROSENTHAL, 1986, p. 336-137), ocorre quando há um pensamento de terceira ordem, que monitora o pensamento de segunda ordem que torna consciente o estado mental de primeira ordem, e o foco da atenção se volta para esse estado de primeira ordem, configurando-se, assim, o escrutínio atento desse estado mental.

Estado mental inconsciente

3o nível

$2^{\circ}$ nível

1º nível

Mundo

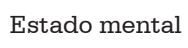
consciente

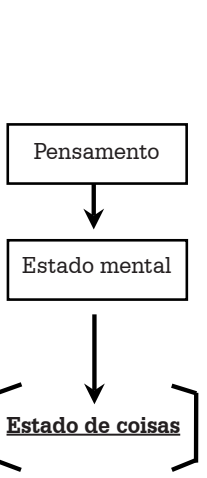

Introspecção de um Estado mental

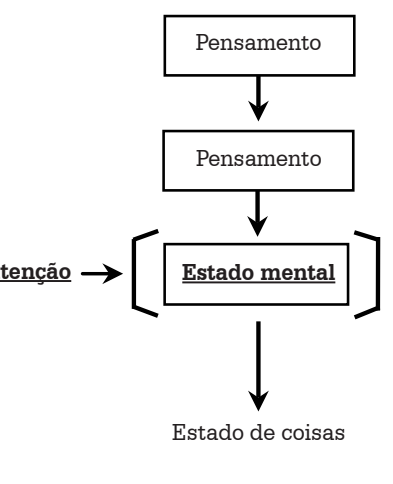

Veritas | Porto Alegre, v. 62, n. 2, maio-ago. 2017, p. 428-452 
Se passarmos para a teoria de Searle, nos vemos diante de um cenário muito diferente, pois essa concepção de Rosenthal tem um caráter, em certo sentido, atomístico, uma vez que ela enfatiza uma multiplicidade de estados mentais (estados mentais de primeira ordem, pensamentos de segunda ordem pensamentos de terceira ordem, etc.) cujas relações extrínsecas constituiriam os fenômenos da consciência (como uma propriedade de estados mentais) e da atenção.

Searle, por seu turno, tenta levar radicalmente a sério a característica da unidade da experiência consciente, e isso o leva a esboçar uma visão em certo sentido holística a respeito da consciência. Ele considera estranha a perspectiva que entende a consciência como uma multiplicidade de blocos constitutivos (building blocks) porque, em uma visão como essa, se formos capazes de disparar o correlato neural ${ }^{15}$ de uma experiência isolada, como a sensação da cor vermelha, então um sujeito inconsciente "poderia ter repentinamente uma experiência consciente de vermelho e nada mais do que isso" (SEARLE, 2002a, p. 54 [82]). Searle admite que pode estar enganado, mas ele acredita que algo assim não é possível, pois sempre vivenciamos fenômenos mentais determinados (como determinadas sensações de cor, ou determinados desejos) integrados a uma experiência unificada, e isso leva Searle a supor que há uma condição neurofisiológica da consciência unificada que é anterior a qualquer estado mental específico: "Apenas um cérebro que já ultrapassou o limiar da consciência, que já possui um campo consciente, pode ter uma experiência visual da cor vermelha." (SEARLE, 2002a, p. 54 [82]).

Ele admite que essa é apenas uma hipótese, e não poderia ser diferente, pois ele não está se pronunciando sobre questões puramente conceituais, mas sim sobre questões que só podem ser decididas através de um estudo empírico do cérebro. ${ }^{16}$ Mas, guiado pela característica da unidade da experiência consciente, Searle especula que há um correlato neural da experiência consciente global. Para tornar essa ideia plausível ele recorre a indícios de que a consciência é, de certo modo, anterior a estados mentais particulares, como ele tenta evidenciar através do seguinte exemplo:

${ }^{15}$ O correlato neural consiste nos "eventos neurobiológicos que estão correlacionados com a consciência" (SEARLE, 2002, p. 49 [73]).

16 "Se esta é a maneira certa de ver as coisas (e, de novo, esta é uma hipótese minha, nada mais) (...)" (SEARLE, 2002, p. 55 [84]). Referindo-se à teoria dos blocos constitutivos e à teoria do campo unificado, ele afirma: "É importante ressaltar que ambas são hipóteses empíricas rivais, a serem provadas por meio de pesquisas científicas e não de argumentos filosóficos." (SEARLE, 2002, p. 54 [82]). 
Imaginemo-nos acordando de um sono sem sonhos em um quarto completamente escuro. Até então não temos um fluxo coerente de pensamento e quase nenhum estímulo perceptivo. Exceto o contato do corpo com a cama e o lençol, não estamos recebendo nenhum estímulo sensível externo. Não obstante, é necessário que haja uma diferença no nosso cérebro entre o estado de vigília mínima no qual estamos agora e o estado de inconsciência no qual estávamos. É essa diferença, a meu ver, o NCC ${ }^{17}$ que teríamos que procurar. E esse estado de vigília é a chamada consciência basal ou de fundo (SEARLE, 2002, p. 54 [83]).

Antes de vivenciarmos a profusão de estados, eventos e processos mentais que povoa nossa vida psicológica, antes que nosso aparato perceptivo seja inundado pelas sensações e percepções oriundas do ambiente circundante, ou que vivenciemos nossas crenças, desejos e emoções, uma condição tem que ser satisfeita: nosso cérebro tem de gerar o campo unificado, em cujo seio todos esses fenômenos mentais poderão existir. De acordo com ele, na situação acima descrita: "seu cérebro produziu um campo de consciência completo, e o que nós precisamos entender é como o cérebro produz esse campo consciente e como o campo existe no cérebro." (SEARLE, 2004, p. 154). Searle ilustra a diferença entre essa consciência basal e a multiplicidade de nossa vida psíquica, continuando o exemplo:

Agora acendemos a luz, levantamo-nos, caminhamos e assim por diante, o que passa a acontecer? Criamos novos estados conscientes? Em certo sentido, é claro que sim, porque antes não estávamos conscientemente atentos aos estímulos visuais como estamos agora. Mas, em relação à totalidade do campo de consciência, as experiências visuais seriam partes de um todo? (SEARLE, 2002, p. 54 [83]).

Embora essa seja uma maneira bastante usual de se pensar a relação entre estados mentais e o campo de consciência, Searle se inclina a pensar de outra forma, em virtude da característica da unidade. Ele não pensa como se os estados mentais fossem como objetos dentro de uma sala, mas sim como se os diversos estados (eventos e processos) mentais fossem modificações do campo de consciência, diferentes formas que esse campo, como um todo, assume. Ele rejeita a metáfora de que os estados mentais são como partes de um todo (a consciência), mas rejeita também a metáfora de um palco, pois ela dá a entender que a consciência é como um fundo constante, diante do qual os diversos atores desempenham

$\overline{17}$ NCC é a abreviatura para "Neural Correlates of Consciousness". 
seus papéis. ${ }^{18} \mathrm{Na}$ visão que ele deduz da característica da unidade, não há a diferença entre o palco e os atores. A unidade da experiência consciente sugere que há apenas a consciência, que assume diversas formas, formas estas correspondentes aos diversos estados, eventos e processos mentais.

Salta aos olhos a diferença entre essa perspectiva holística de consciência e a visão de Rosenthal, pois na visão do campo unificado não há lugar para a miríade de estados mentais, ao longo de diversos níveis, com suas relações extrínsecas. Na visão de Searle, a consciência é um grande todo, e é nesse todo que teremos de procurar os elementos que constituem a autoconsciência pré reflexiva. Essa não é uma tarefa simples, pois ao formular essa sua hipótese de que a consciência é um campo unificado, Searle ressalta o aspecto holístico e não dá grandes detalhes sobre a estrutura desse "campo" de consciência. Porém, no meu modo de entender, uma pista bastante promissora a ser seguida (pista que ajuda a esclarecer o papel da autoconsciência pré reflexiva na teoria de Searle) é a distinção que ele traça entre o centro e a periferia da atenção.

Para formular claramente minha leitura da teoria de Searle (que lastreia a tese defendida no presente trabalho), o ponto é que os elementos que permanecem na periferia da atenção são apreendidos implicitamente pelo sujeito consciente. Se aquilo que está no centro da atenção (seja a percepção de um objeto externo, seja a lembrança de uma situação passada, seja uma determinada vivencia emocional) é apreendido de modo explícito, de modo a ser objeto do pensamento e da ação do sujeito, aquilo que está na periferia da atenção se doa, se apresenta ao sujeito de modo implícito, indireto. ${ }^{19}$ Para elucidar esse modo implícito de apreensão dos estados (eventos e processos) mentais, é

18 "Não devemos pensar minhas novas experiências como novos atores no palco da consciência, mas como novos contornos, novas formas ou novas características no campo unificado da consciência. Qual é a diferença? A metáfora do proscênio nos oferece um fundo de cena constante, com vários atores presentes nele. A meu ver, isso está errado. Há somente o campo consciente unificado, nada mais, e este assume diferentes formas." (SEARLE, 2002, p. 55 [84]).

${ }^{19}$ É interessante notar que em sua discussão da teoria de Sartre sobre a consciência (discussão feita a partir do ponto de vista da filosofia analítica), Gregory McCulloch entende que a ideia de uma apreensão implícita desempenha um importante papel na teoria do filósofo francês. De acordo com McCulloch: "Sartre considera que todo episódio consciente põe um objeto intencional. Mas entre tais objetos intencionais estão os próprios atos de consciência. Eu posso pensar sobre a Torre Eiffel, e então pensar sobre esse próprio ato (...) A esse modo de autoconsciência [self-awareness] ele chama de 'consciência reflexiva' ou 'autoconsciência tética' (...). Entretanto, Sartre enfatiza que essa não é a única forma de autoconsciência de que nós desfrutamos. Ele alega que em adição a essa autoconsciência reflexiva e explícita, que é apenas um caso especial de um ato de consciência pondo um objeto intencional, nós também sempre estamos ao menos implicitamente autoconscientes, de um modo especial, mesmo se não estamos explicitamente refletindo." (MCCULLOCH, 1994, p. 9, grifo meu). 
indispensável examinar as colocações de Searle a respeito dos conceitos de autoconsciência e introspecção.

\section{Autoconsciência e introspecção}

No sexto capítulo de $A$ redescoberta da mente, onde ele oferece uma exposição introdutória de sua visão sobre a estrutura da consciência, Searle reserva um espaço para se posicionar em relação a três teses a respeito da consciência que ele considera equivocadas: (1) a tese de que todos os estados conscientes são autoconscientes; (2) a tese de que a consciência é conhecida por uma faculdade de introspecção; e (3) a tese de que nosso conhecimento de nossos próprios estados conscientes é incorrigível (SEARLE, 1992, p. 141 [203]). Para os nossos presentes objetivos, apenas o exame dos conceitos de autoconsciência e de introspecção se mostra central. Em suas considerações sobre esses conceitos, Searle considera importante distinguir entre um sentido técnico desses termos e um sentido de senso comum.

A visão de Searle é que as teses relativas à autoconsciência e à introspecção podem ser, se tomadas em um sentido, trivialmente verdadeiras, mas se tomadas no outro sentido elas se mostram falsas. No caso da autoconsciência, Searle entende que, num sentido ordinário, "autoconsciência" pode significar duas coisas: (a) uma consciência voltada para a própria persona pública (consciência que subjaz, por exemplo, ao sentimento de vergonha); ou (b) uma consciência voltada para os próprios estados mentais. Se tomarmos o termo "autoconsciência" nesse sentido, então a tese de que todo estado de consciência é autoconsciente se mostra claramente falsa, pois na maior parte das vezes nos encontramos em diversos estados conscientes sem desfrutar de autoconsciência em nenhum desses dois sentidos ordinários. De acordo com ele:

No sentido ordinário de autoconsciência, conforme explicado nos casos dois e três ${ }^{20}$, simplesmente parece falso que todo caso de consciência seja um caso de autoconsciência. No sentido ordinário, autoconsciência é uma forma extremamente sofisticada de sensibilidade, e provavelmente possuída somente por seres humanos e, talvez, por um número reduzido de outras espécies (SEARLE, 1992, p. 142-43 [205]).

Neste ponto, a distinção de Rosenthal entre consciência introspectiva e não introspectiva se mostra decisiva, pois o que Searle está dizendo é que não é verdade que em todo estado de consciência sempre temos consciência de nós mesmos (seja enquanto pessoas, seja uma consciência

${ }^{20}$ Cf. as duas próximas notas de rodapé. 
de nossos próprios estados mentais). E Rosenthal também entende que podemos nos encontrar em diversos estados mentais conscientes sem que voltemos nossa atenção para eles (ROSENTHAL, 1997, p. 730).

Para exemplificar o que seria autoconsciência enquanto uma consciência da própria pessoa, Searle formula um exemplo baseado no sentimento de vergonha ${ }^{21}$, ao passo que a autoconsciência enquanto uma consciência dos próprios estados mentais é exemplificada com uma situação em que o sujeito volte a sua atenção para os próprios estados mentais que ele vivencia em um dado instante, o que corresponde à noção de Rosenthal de uma consciência introspectiva. ${ }^{22}$

Entretanto, apesar de recusar a tese de que toda consciência é autoconsciente no sentido ordinário de "autoconsciência", Searle, por outro lado, aceita essa tese se tal termo for entendido em um sentido técnico, e ele baseia essa sua aceitação, justamente, na distinção que ele faz entre o centro e a periferia da atenção. Para explicar sua aceitação, ele afirma:

Necessariamente, portanto, a afirmação de que toda consciência envolve autoconsciência é proposta em um sentido técnico. Qual é esse sentido? Vimos em nossa discussão da distinção entre o centro e a periferia, que podemos sempre deslocar a nossa atenção dos objetos no centro da consciência para aqueles na periferia, de forma que o que era anteriormente periférico torna-se central (SEARLE, 1992, p. 143 [205-6]).

É justamente nesse contexto que entra em cena a adesão de Searle à tese de que há uma autoconsciência pré reflexiva dos estados mentais, pois os estados mentais que estão na periferia da atenção são vistos por

\footnotetext{
21 "Primeiro, suponha que eu esteja sentado num restaurante comendo um bife. No sentido ordinário, não estaria caracteristicamente autoconsciente de modo algum. Podia estar consciente de que o bife é gostoso, o vinho com que o estou regando é muito novo, as batatas estão cozidas demais, etc. Mas não há nenhuma autoconsciência. Segundo, suponha que de repente eu note que todos, no restaurante, estão me olhando espantados. Eu podia perguntar a mim mesmo por que estariam tão boquiabertos daquele jeito, até descobrir que, num acesso de distração, eu tinha esquecido de vestir minhas calças. Estou sentado ali de cuecas. Tal circunstância podia produzir sensações que descreveríamos normalmente como 'autoconsciência aguda'. Estou ciente de minha própria pessoa e do efeito que estou provocando nos outros. mesmo aqui, porém, minha autoconsciência não é dirigida aos meus próprios estados conscientes." (SEARLE, 1992, p. 142 [204-5]).

22 "Terceiro, imagine que eu esteja agora no restaurante completamente vestido, e de repente concentre toda a minha atenção nas experiências conscientes que estou tendo no restaurante, saboreando a refeição e bebendo o vinho. De súbito, por exemplo, parece-me que estive indesculpavelmente me refestelando numa espécie de autoindulgência hiperestética por ter investido tempo, esforço e dinheiro para assegurar-me essas experiências gastronômicas. Subitamente, isso me parece de trop. Este também parece um caso de autoconsciência no sentido ordinário, mas difere do segundo porque a autoconsciência é dirigida aos estados de consciência do próprio agente, e não à sua persona pública." (SEARLE, 1992, p. 142 [205]).
} 
ele como estados conscientes, e, enquanto "parte" do campo unificado de consciência, tais estados podem ser deslocados a qualquer momento para o centro da atenção. Mas durante o tempo em que eles permanecem na periferia, esses estados são, sim, apreendidos pelo sujeito consciente, mesmo que de um modo implícito, indireto, pois se não fossem (de algum modo) apreendidos, esses estados seriam inconscientes.

Quando estamos conscientes - quando nosso cérebro produz o campo unificado que constitui a consciência basal - o foco de nossa atenção pode estar em objetos e estados de coisas extramentais, no que estes objetos e estados de coisas são apreendidos por estados intencionais (consciência transitiva). Mas o foco de nossa atenção pode ser deslocado, facilmente, para estes estados intencionais, eles mesmos, e é nesse fato que Searle fundamenta sua aceitação de uma certa forma de autoconsciência, pois se o estado de consciência intencional pode, a qualquer momento, estar no centro da atenção (sendo portando apreendido explicitamente), então esse estado (no meu modo de entender) tinha que estar sendo apreendido implicitamente, quando o foco da atenção estava no objeto "exterior". Nas palavras de Searle:

De modo semelhante, parece que podemos sempre deslocar nossa atenção do objeto da experiência consciente para a experiência em $\mathrm{si}^{23}$ (...). Parece-me que poderíamos obter um sentido de "autoconsciência" em que seja trivialmente verdadeiro que qualquer estado consciente é autoconsciente: em qualquer estado consciente, podemos deslocar nossa atenção para o estado em si. Posso centrar minha atenção, por exemplo, não na cena à minha frente, mas na experiência de meu ato de ver essa mesma cena. E porque a possibilidade desse deslocamento de atenção estava presente no próprio estado, podemos dizer, neste sentido técnico extremamente especial, que todo estado consciente é autoconsciente. (SEARLE, 1992, p. 143 [206]).

Poderíamos representar essa concepção através de um diagrama, no qual o círculo representa o campo unificado de consciência, os pontos representam estados (eventos e processos) mentais particulares ${ }^{24}$, a

${ }^{23}$ É interessante notar que, discorrendo sobre a reflexão acerca de uma imagem mental, Sartre se expressa em termos muito semelhantes: "Assim, a imagem enquanto imagem só é descritível por um ato de segundo grau, com o que o olhar se desvia do objeto para dirigir-se sobre a maneira como o objeto é dado. É o ato reflexivo que permite o julgamento 'eu tenho uma imagem'." (SARTRE, 1996, p. 15).

${ }^{24} \mathrm{O}$ fato de os pontos serem representados no interior do círculo não deve sugerir que os estados mentais são como que objetos no interior de uma sala. Essa é uma dificuldade da representação pictórica da teoria de Searle, mas os pontos são pensados para representar modificações do campo, como se fossem protuberâncias e depressões em uma superfície, que é um todo: "Você não está criando uma nova consciência, você está modificando o campo 
seta representa a relação intencional entre um estado consciente e o seu objeto, e os colchetes representam o foco da atenção.
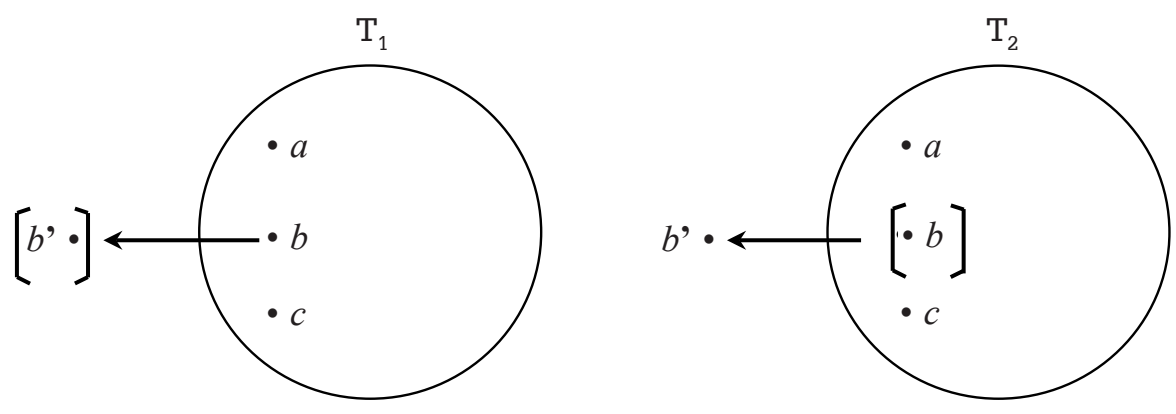

No diagrama acima, o objeto (ou estado de coisas) b' é apreendido intencionalmente pela percepção $b$, que é um estado mental consciente, consistindo em uma consciência (transitiva) de b'. Em qualquer tempo $\mathrm{T}_{1}$, o foco da atenção pode estar voltado para esse objeto extramental, mas nesse mesmo tempo $\mathrm{T}_{1}$ os estados mentais $a, b$ e $c$ permanecem na periferia da atenção (assim como outros objetos e estados de coisas externos além de $b^{\prime}$ ), e se eles estão nessa periferia, isso significa que, a qualquer momento, o foco da atenção pode se deslocar para eles. Em qualquer tempo $\mathrm{T}_{2}$, cronologicamente posterior $\mathrm{a} \mathrm{T}_{1}$, o foco da atenção pode ser deslocado do objeto extramental b' para, por exemplo, a percepção $b$ acerca dele. Mas, evidentemente, esse foco da atenção pode ser posteriormente deslocado da percepção $b$ para qualquer outro estado mental, como a e $c .{ }^{25}$ Se a atenção se volta para um desses estados mentais, ele passa a ser apreendido de modo explícito, ele se torna o foco para o qual as considerações (e operações mentais) do sujeito se dirigem. Porém, se durante o tempo em que não são apreendidos de modo explícito os estados mentais conscientes tem a capacidade de se tornar o foco, isso significa que eles não estão (é claro) completamente desvinculados da consciência. Se durante o tempo em que não estão no foco, esses estados mentais não estão desvinculados da consciência, isso significa que eles são apreendidos, mesmo que não de um modo explícito. Minha leitura é

consciente preexistente. No modelo do campo unificado nós devemos pensar em inputs perceptuais não como se estivessem criando blocos constitutivos de consciência, mas como se produzissem protuberâncias e depressões no campo consciente que já existe antes de termos essas percepções." (SEARLE, 2004, p. 155).

${ }^{25}$ Suponhamos que $b$ é a percepção de um objeto, e que a é uma lembrança de uma situação passada na qual esse mesmo objeto foi visto. É claro que a qualquer momento o foco da atenção pode ser deslocado da percepção para a lembrança (se eu opero uma introspecção dessa lembrança). 
que, se eles podem se tornar, a qualquer instante, o centro das atenções, isso significa que eles são apreendidos implicitamente, sem qualquer reflexão, o que constitui, portanto, uma forma de autoconsciência pré reflexiva.

Mas como se realiza, mais exatamente, esse processo de se colocar determinado estado mental no foco da atenção? Como é que esse foco da atenção se desloca para o objeto extrapsíquico para o estado mental que é acerca desse objeto e, depois, eventualmente, se desloca de um estado mental para outro? Essas questões podem ser, em parte, respondidas através de um exame do posicionamento de Searle a respeito da tese da introspecção. Assim como no caso do conceito de autoconsciência, Searle também distingue entre um conceito técnico e um conceito ordinário de introspecção. Mas, neste caso, é o conceito ordinário que seria perfeitamente aceitável, ao passo que o conceito técnico expressaria uma visão errônea sobre a consciência.

Ao defender que nossos estados de consciência são conhecidos por nós mesmos através de uma faculdade especial de introspecção, certos filósofos estariam apenas cometendo o erro de tomar literalmente uma metáfora a respeito de nosso autoconhecimento. A palavra "introspecção" (de spectare - ver) sugere que nosso conhecimento de nossos próprios estados conscientes se dá de modo análogo à nossa visão de objetos externos. Mas Searle considera essa concepção completamente equivocada, pois "no caso da visão, nós temos uma distinção clara entre o objeto visto e a experiência visual que o sujeito perceptor tem quando ele percebe o objeto." (SEARLE, 1992, p. 144 [207]). Mas distinções desse tipo, de acordo com ele, não se aplicam ao caso de nosso conhecimento de nossos próprios estados de consciência, pois não podemos nos distanciar e "olhar" para tais estados como se eles fossem um objeto que existisse independentemente de nosso ato de olha-lo. De acordo com Searle, não podemos fazer a distinção entre "o objeto inspecionado e a sua inspeção" (SEARLE, 1992, p. 144 [208]).

Por outro lado, o que se chama, metaforicamente, de um "olhar" (spectare) "para dentro" (intro), pode ser compreendido em termos de um "voltar a atenção para dentro de si" (SEARLE, 1992, p. 144 [207]), de um exame cauteloso e próximo (closely) (ibid.) dos próprios estados mentais, ou ainda em termos de "dirigir um estado mental a outro" (SEARLE, 1992, p. 144 [208]).

Ao conceber a introspecção (em sentido ordinário) nesses termos, Searle está admitindo a possibilidade de se dirigir um estado mental (que ocorre em dado momento no campo unificado de consciência) para um outro estado mental (ocorrendo nesse mesmo campo unificado) e, através desse direcionamento, colocar o foco da atenção sobre este 
segundo estado mental (ao qual o primeiro se direciona) e examina-lo de modo cuidadoso. Nesse sentido, Searle parece conceber a introspecção de um modo similar a Rosenthal, pois, na visão de ambos, a introspecção ocorreria quando um estado mental se direciona para um outro estado mental, colocando este último no foco da atenção. Mas a diferença é que na teoria de Rosenthal o estado mental que se direciona a outro é inconsciente, enquanto que na teoria de Searle ele também tem que ser um estado consciente (já que ele é um estado mental efetivo). ${ }^{26} \mathrm{De}$ acordo com Searle, tanto o estado mental que se direciona para outro, quanto este, que é objeto daquele, ocorrem efetivamente no campo unificado de consciência do sujeito, ao mesmo tempo.

A partir dessas considerações, a visão de Searle sobre a introspecção pode ser representada através de um diagrama modificado, no qual o estado intencional $b$ é representado como objeto de um segundo estado intencional $d$, que no tempo $\mathrm{T}_{2}$ coloca o estado $b$ no foco da atenção do sujeito.

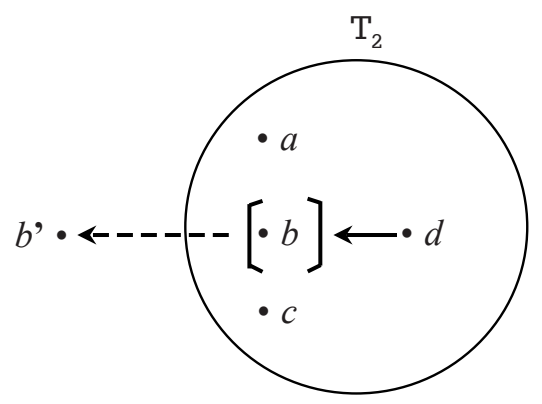

Neste diagrama, a seta ligando o estado $b$ ao objeto extramental b' é feita com linha tracejada, para representar o fato de que a relação intencional com esse objeto b' passou para a periferia da atenção, uma vez que é o estado mental $b$, ele mesmo, que se encontra agora no foco.

Em resumo, temos o seguinte quadro: quando o organismo do sujeito $S$ está consciente, seu cérebro gera um campo unificado de consciência qualitativa e subjetiva (representado pelo círculo) que existe como um

\footnotetext{
${ }^{26} \mathrm{Na}$ perspectiva de Searle, como vimos, "não temos noção do mental independentemente de nossa noção de consciência" (SEARLE, 1992, p. 18 [31]). Sendo assim, fenômenos mentais, propriamente falando, ou são conscientes ou são o tipo de coisa que pode se tornar consciente (isto é, uma disposição para a causação de um fenômeno mental consciente - cf. SEARLE, 1992, p. 161 [231]). Se um estado mental opera uma introspecção, isto é, se ele inspeciona um outro estado mental, então ele é efetivo (ele existe de fato na vivência do sujeito), e se ele é efetivo, então ele tem que ser consciente, mesmo que esteja na periferia da atenção.
} 
substrato, cujas modificações (talvez pudéssemos dizer os "acidentes") são os diversos estados, eventos e processos mentais vivenciados pelo sujeito $S$ (representados no diagrama pelos pontos $a, b, c$ e $d$ ). Na concepção de Searle, todas as modificações do campo unificado, na medida em que existem apenas enquanto modificações da consciência, tem que ser conscientes, mesmo que só de uma forma implícita, isto é, mesmo que permaneçam na periferia da atenção do sujeito. Em situações nas quais não há introspecção (como na situação representada pelo círculo em $\mathrm{T}_{1}$ na figura anterior) a atenção do sujeito está voltada para objetos e/ou estados de coisas extramentais, mas mesmo assim todos os seus estados mentais permanecem implicitamente conscientes, ou seja, na periferia da atenção. Em tais situações, sem introspecção, todo o campo de consciência do sujeito é perpassado (de um modo que não fica claro) por uma autoconsciência implícita, que pode ser caracterizada como pré reflexiva (ou não introspectiva, nos termos de Rosenthal). Isso significa que, na visão de Searle, a autoconsciência é uma característica constitutiva do próprio campo unificado, mesmo quando não há introspecção (embora sua teoria não explique como essa característica é efetivada no campo unificado). E o mesmo vale para as situações nas quais ocorre introspecção, pois, nessas situações, o foco da atenção está voltado para um estado mental, mas todos os outros estados mentais do sujeito permanecem implicitamente conscientes, evidenciando que a autoconsciência (no sentido técnico do termo) permanece uma característica constitutiva do campo unificado de consciência qualitativa e subjetiva.

\section{Considerações finais}

Conforme foi discutido na introdução do presente artigo, existem elementos de nossa experiência consciente que dão impulso à intuição de que a consciência é uma característica intrínseca do mental, intuição que é vista como afinada com o senso comum (ROSENTHAL, 1986, p. 331). Searle é declaradamente um defensor do ponto de vista de que a consciência é essencial aos fenômenos mentais (SEARLE, 1992, p. 18 [31]; p. 84 [125-26]), e isso pode ser visto como um obstáculo intransponível para qualquer tentativa de explicação conceitual do fenômeno da consciência. Rosenthal entende que se assumirmos que o próprio fundamento de ser um estado mental é ser um estado consciente, então "nós não podemos explicar o que torna conscientes os estados que são conscientes apelando a uma explicação anterior da mentalidade, uma vez que nessa visão a mentalidade pressupõe a própria consciência" (ROSENTHAL, 1986, p. 330). 
Searle, por sua vez, aceita alegremente a impossibilidade de definir a consciência (SEARLE, 1992, p. 83 [123]), e, desse modo, ele a concebe como algo opaco a qualquer tentativa de explicação conceitual. Entendo que tal opacidade pode ser facilmente percebida na concepção de Searle sobre a estrutura da autoconsciência, discutida no presente trabalho, pois a maneira como ele apresenta essa estrutura é vaga e lacunar. Searle entende a consciência como um campo unificado, e entende os fenômenos mentais como modificações desse campo. Mas sobre o modo como a autoconsciência existe nesse campo, ele tem pouco a dizer. Na teoria de Searle, a autoconsciência perpassa todo o campo unificado, uma vez que tudo o que existe nesse campo, mesmo que esteja na periferia da atenção, pode se tornar o foco, o que (segundo a interpretação defendida no presente texto) significa que aquilo que estava na periferia já era apreendido implicitamente pelo campo de consciência unificada. Mas como se dá exatamente essa apreensão implícita?

$\mathrm{Na}$ teoria de Rosenthal, temos o pensamento de ordem superior (inconsciente) que monitora o fenômeno mental que possui a propriedade da consciência de estado. Na teoria de Searle, não temos nenhuma pista de como essa apreensão implícita poderia se dar, e essa falha da teoria parece confirmar a crítica de Rosenthal ao que ele chama de "concepção cartesiana" da consciência, isto é, a concepção (explicitamente defendida por Searle) de que a consciência é uma característica intrínseca e definidora de tudo aquilo que é mental. Em uma concepção como essa, a explicação da consciência parece impossível, pois, por um lado, não se consegue explica-la em termos do que não é mental (como comportamento, processos cerebrais, padrões causais, etc.) e, por outro lado, se tudo o que é mental é consciente, então toda explicação da consciência em termos de fenômenos mentais será circular e não informativa (ROSENTHAL, 1997, p. 735).

A ideia de um campo unificado de consciência, que Searle estabelece como uma hipótese, guiado pela unidade que vivenciamos em nossa experiência, é uma ideia interessante, pois, por um lado, se coaduna com nossas vivências (nas quais os diversos fenômenos mentais se unificam numa experiência única) e, por outro lado, nos convida a pensar sobre a consciência de um ponto de vista pouco usual (um ponto de vista segundo o qual é a própria consciência que é o substrato de nossos estados, eventos e processos mentais). Todavia, além de seu caráter especulativo (que Searle admite), essa ideia tem algo de metafórico, pois transfere uma noção do campo das ciências físicas (do estudo da gravidade e do eletromagnetismo) para o campo do estudo da consciência, sem fornecer elementos conceituais para caracterizar 
esse "campo" de consciência de modo bem definido. De que modo esse, suposto, campo apreende implicitamente os estados mentais que existem como modificações dele próprio? Essa é uma questão importante, sobre a qual Searle não se manifesta. O caráter metafórico do conceito de um "campo unificado" de consciência (qualitativa e subjetiva), no meu entender, indica uma obscuridade da teoria que, certamente, não contribui para que tal teoria da consciência pareça plausível.

\section{Referências}

ARMSTRONG. A. "What is Consciousness?". In: BLOCK, N.; FLANAGAN, O.; GÜZELDERE, G. (Org.). The Nature of Consciousness: Philosophical Debates. Cambridge, Mass.: MIT Press, 1997. p. 721-728,

BRENTANO, F. Psychologie vom empirischen Standpunkt. 2. ed. Leipzig: Felix Meiner, 1924. 1995.

Psychology from an empirical standpoint. London: Routledge \& Kegan Paul,

CHALMERS, D. "Facing Up To The Problem of Consciousness". Journal of Consciousness Studies, 2, 3 (1995), p. 200-219.

KRIEGEL, U. "Consciousness and Self-Consciousness". The Monist, 87, 2 (2004), p. $182-205$.

MCCULLOCH, G. Using Sartre: An Analitical Introduction to Early Sartrean Themes. Londres; Nova Iorque: Routledge, 1994.

PRATA, T. A. "A concepção disposicional do inconsciente na filosofia da mente de John Searle". In: Revista Reflexões, 6, 11 (2017), p. 201-216.

ROSENTHAL, D. "Two Concepts of Consciouness". In: Philosophical Studies, 49 (1986), p. 329-359.

. "A Theory of Consciousness". In: BLOCK, N.; FLANAGAN, O.; GÜZELDERE, G. (Org.). The Nature of Consciousness: Philosophical Debates. Cambridge, Mass.: MIT Press, 1997. p. 729-753.

SARTRE, J.-P. La transcendence de l'Ego - esquisse d'une description phénoménologique. Paris: Vrin, 1966.

. "A transcendência do ego - esboço de uma descrição fenomenológica". In: Cadernos Espinosanos, XXII, (2010), p. 183-228.

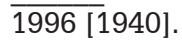

. O imaginário: psicologia fenomenológica da imaginação. São Paulo: Ática,

SEARLE, J. R. The Rediscovery of the Mind. Cambridge, Mass.; London: MIT Press, 1992.

. A redescoberta da mente. São Paulo: Martins Fontes, 1997.

2002.

. Consciousness and Language. Cambridge (UK): Cambridge University Press, 
. Mind: A Brief Introduction. Oxford: Oxford University Press, 2004.

. Consciência e linguagem. São Paulo: Martins Fontes, 2010.

. Seeing Things as They Are: A Theory of Perception. Oxford: Oxford University Press, 2015.

TUGENDHAT, E. Selbstbewusstsein und Selbstbestimmung: Sprachanalytische Interpretationen. Frankfurt a.M.: Suhrkamp, 1981.

\section{Endereço postal:}

Universidade Federal de Pernambuco

Centro de Filosofia e Ciências Humanas, 15o andar,

Av. Prof. Morais Rego, s/n. - Cidade Universitária

Recife, PE, Brasil

Data de recebimento: 27-01-2017

Data de aceite: 05-09-2017 